\title{
Digestion rate of dietary starch affects the systemic circulation of lipid profiles and lipid metabolism-related gene expression in weaned pigs
}

\author{
Fugui Yin ${ }^{1,2} \dagger$, Yulong Yin $^{1,3 *}$, Zhenzhen Zhang $^{3} \dagger$, Mingyong Xie $^{3}$, Ju Huang ${ }^{1,2}$, Ruilin Huang ${ }^{1}$ \\ and Tiejun $\mathrm{Li}^{1}$ \\ ${ }^{1}$ Research Center for Healthy Breeding of Livestock and Poultry, Hunan Engineering and Research Center of Animal and \\ Poultry Science and Key Laboratory for Agro-ecological Processes in Subtropical Region, Institute of Subtropical Agriculture, \\ The Chinese Academy of Sciences, 410125 Hunan, People's Republic of China \\ ${ }^{2}$ The Graduate School of the Chinese Academy of Sciences, Beijing 100049, People's Republic of China \\ ${ }^{3}$ National Key Laboratory of Food Science and Technology, College of Life Science, Nanchang University, Nanchang, Jiangxi \\ 330047, People's Republic of China
}

(Received 4 August 2010 - Revised 15 December 2010 - Accepted 6 January 2011 - First published online 23 February 2011)

\section{Abstract}

The present study was conducted to investigate the effect of digestion rate of dietary starch on postprandial systemic circulating glucose, insulin and lipid profiles, and the activity and gene expression of lipid metabolism-related enzymes in weaned pigs. A total of twenty-four weaned pigs, surgically fitted with a catheter in the jugular vein, were randomly assigned to three dietary treatment groups, representing the high digestion rate starch (HDRS) group, the moderate-digestion rate starch (MDRS) group and the low-digestion rate starch (LDRS) group. The amylopectin:amylose ratios in the diets of each group were $27 \cdot 6: 1,27 \cdot 6: 8 \cdot 5$ and $1: 27 \cdot 6$, respectively. The serum concentrations of glucose, TAG, total cholesterol, LDL-cholesterol and HDL-cholesterol in the HDRS group were increased to the peak point at postprandial $1 \cdot 5,2 \cdot 5,2 \cdot 5,1 \cdot 5$ and $1 \cdot 5 \mathrm{~h}$, those in the MDRS group were at postprandial $2 \cdot 5,3 \cdot 5,3 \cdot 5,3.5$ and $3.5 \mathrm{~h}$ and those in the LDRS group were at postprandial $2 \cdot 5,3 \cdot 5,3 \cdot 5,1.5$ and $3.5 \mathrm{~h}$, respectively. The serum concentration of insulin in the HDRS group was higher $(P<0 \cdot 05)$ than those in the MDRS group, and those in the MDRS group was also higher $(P<0.05)$ than those in the LDRS group at postprandial 0.5 , 1.5 and $2.5 \mathrm{~h}$, respectively. The serum concentrations of acetate, propionate and butyrate in the HDRS group were higher $(P<0.05)$ than those in the MDRS group, and those in the MDRS group were higher $(P<0.05)$ than in the LDRS group in each feeding cycle, in turn, respectively. The activity of fatty acid synthase (FAS) in the liver and abdominal adipose tissues, that of acetyl CoA carboxylase (ACC) in the myocardium and interscapular brown adipose tissues and that of the ATP-citrate lyase (ATP-CL) in the liver and interscapular brown adipose tissues in pigs of the HDRS group were higher $(P<0.05)$ than that of the MDRS group. The mRNA levels of FAS in the myocardium, liver and interscapular brown adipose tissues of pigs in the HDRS group were higher $(P<0 \cdot 05)$ than those of the MDRS group. The activities and mRNA levels of FAS, ACC and ATP-CL in the myocardium, liver, abdominal and interscapular brown adipose tissues of the HDRS group were higher than those of the LDRS group. We conclude that the digestion rate of dietary starch affected not only the postprandial systemic circulating levels of glucose and insulin but also the lipid metabolism in weaned pigs. Dietary starch with higher digestion rate produces higher blood glucose and insulin response, ameliorates the blood lipid profiles and up-regulates the activity and gene expression profile of lipid metabolism-related genes in weaned pigs.

\section{Key words: Digestion rate: Starch: Lipogenic enzymes: Gene expression profile: Weaned pigs}

Starch is the main energy-yielding component of the daily diet for most mammals ${ }^{(1)}$. The major physiological properties of starch are characterised in the release of glucose as a source of energy for the body and the timeline of digestion in the small intestine ${ }^{(2)}$. Generally, starch is thought to be a mixture of amylose and amylopectin, or resistant and digestible $\operatorname{starch}^{(3,4)}$. High resistant starch level is associated with a high level of amylose ${ }^{(5)}$. Our previous in vitro digestibility trial indicated that starch with an amylopectin:amylose ratio of $1: 27 \cdot 6$ was digested only $45.83 \%$ within $4 \mathrm{~h}$, whereas those with ratios of $27 \cdot 6: 8 \cdot 5$ and $27 \cdot 6: 1$ were digested up to 90.95 or $98.77 \%$ in the same time period ${ }^{(6)}$. In vivo, the digestion rate of dietary starch will affect the circulating level of glucose, as well as other absorbed nutrients such as small

\footnotetext{
Abbreviations: ACC, acetyl CoA carboxylase; ATP-CL, ATP-citrate lyase; FAS, fatty acid synthase; GAPDH, glyceraldehyde-3-phosphate dehydrogenase; HDRS, high digestion rate starch; LDRS, low digestion rate starch; MDRS, moderate digestion rate starch.
}

*Corresponding author: Dr Y. Yin, fax +86 73184612685 , email yinyulong@isa.ac.cn

† F. Yin and Z. Zhang are joint first authors. 
euthanised at 10.00 hours. About $5 \mathrm{~g}$ of the myocardium, liver, abdominal adipose and interscapular brown adipose tissues were collected and immediately frozen in liquid $\mathrm{N}_{2}$, and stored at $-80^{\circ} \mathrm{C}$ for the determination of the activities of lipogenic enzymes, respectively. The tissue samples ( $2 \mathrm{~g}$ ) were cut into approximately $5 \times 5 \times 1-2 \mathrm{~mm}$ pieces and placed immediately in RNAlater (Applied Biosystems, Austin, TX, USA), and stored at room temperature for a few hours, respectively, then frozen at $-20^{\circ} \mathrm{C}$ until further processing for RNA extraction and complementary DNA synthesis.

\section{Serum analyses}

The serum concentrations of glucose, TAG, total cholesterol, LDL-cholesterol, HDL-cholesterol and SCFA (including acetate, propionate and butyrate) were determined using the Automatic Biochemical Analyser (Beckman, Miami, FL, USA) with corresponding kits (commercially available from Leadman Biochemistry Technology Company, Beijing, China). The serum insulin concentration was analysed using a commercially available ${ }^{125}$ I Radio Immunoassay Analyser kit (Beijing North Institute of Biological Technology, Beijing, China) with the $\gamma$-calculating instrument GC-300 (Zhongjia Company, Beijing, China), according to the manufacturers' instructions.

\section{Lipogenic enzyme activity analyses}

The protocol for lipid metabolism-related enzyme activity analyses in the myocardium, liver, abdominal adipose and interscapular brown adipose tissues was as described previously ${ }^{(25)}$. Briefly, approximately $1 \mathrm{~g}$ of the tissue sample was rinsed, blotted dry, weighed and placed in $8 \mathrm{ml}$ ice-cold $20 \mathrm{~mm}$-riffs $\mathrm{HCl}$ buffer ( $\mathrm{pH} 7 \cdot 8$ ) containing $0.2 \%$ Triton X100. The tissue was minced finely with scissors, homogenised manually with a Teflon-pestle homogeniser and centrifuged at $30000 \mathbf{g}$ for $20 \mathrm{~min}$. After removal of the fat cake, the resulting supernatant was decanted, and the pellet was re-suspended in $5 \mathrm{ml}$ isolation medium, re-homogenised and centrifuged as before. The supernatant was combined with that obtained after the first centrifugation step and used for enzyme assay. The activities of FAS (EC 2.3.1.85) and ATP-citrate lyase (EC 4.1.3.8) were measured as described previously ${ }^{(26)}$. All assays were performed in duplicate at $37^{\circ} \mathrm{C}$ using a Biochrom ultrosprc 3100 spectrophotometer (Biochrom, Science Park, Cambridge, UK). The absorbance change both against time and enzyme concentration was linear. ACC (EC 6.4.1.2) activity was measured by the $\mathrm{H}^{14} \mathrm{CO}_{3}$-fixation assay according to the method of Salati \& Clarke ${ }^{(27)}$. All assays were conducted in the range of linearity with respect to the amount of enzyme and time. Soluble protein in the tissue supernatants was measured according to the method as described previously ${ }^{(28)}$, using bovine serum albumin as the standard. All reagents were obtained from Sigma (St Louis, MO, USA).

\section{Gene expression profiles of lipogenic enzymes}

The gene expression profile of lipid metabolism-related enzymes was determined according to the following protocol. Briefly, approximately $100 \mathrm{mg}$ of the tissue sample was homogenised using a JT-B homogeniser (Luohe Jintian Institute of Test Equipment, Luohe, Henan, China). Total RNA was isolated from each homogenised tissue by using TRIZOL reagent (Invitrogen, Inc., Carlsbad, CA, USA) and then treated with DNase I (Invitrogen) as described by the manufacturer. The RNA quality was checked by $1 \%$ agarose gel electrophoresis, stained with ethidium bromide $(10 \mu \mathrm{g} / \mathrm{ml})$. The RNA with an optical density 260/280 ratio between 1.8 and 2.0 was performed with Oligo (dT) 20 and Superscript II reverse transcriptase (Invitrogen) ${ }^{(29)}$. The quantitative PCR assays were performed using the Brilliant SYBR Green quantitative PCR Master Mix (Stratagene, La Jolla, CA, USA) and a Stratagene MX4000 Thermal Cycler (Stratagene). Briefly, a $10 \mu$ l volume reaction system contained $0.4 \mu \mathrm{l}$ of the complementary DNA template, $5 \mu \mathrm{l}$ of the SYBR Green Mix and $0 \cdot 3 \mu$ l of each of the forward and reverse primers and $4 \mu \mathrm{l}$ of double distilled water. The amplification programme started at $95^{\circ} \mathrm{C}$ for $30 \mathrm{~s}$ followed by forty cycles of $95^{\circ} \mathrm{C}$ for $5 \mathrm{~s}$, the gene-specific annealing temperature for $30 \mathrm{~s}$ and extension at $72^{\circ} \mathrm{C}$ for $30 \mathrm{~s}$. Fluorescence measurements were collected after each annealing during the cycles. PCR primers targeting FAS and ACC were as described previously ${ }^{(30)}$, while those targeting ATP-CL and glyceraldehyde-3-phosphate dehydrogenase (GAPDH) were designed with the Primer Premier (Premier Biosoft International, Palo Alto, CA, USA) based on the available porcine GenBank sequences (Table 2). GAPDH was used as an internal reference gene to normalise target gene transcript levels. The identity of each product was confirmed by the dideoxy-mediated chain termination sequencing at Sangon Biotechnology, Inc. (Shanghai, China). The relative expression ratio $(R)$ of mRNA was calculated by

Table 2. Quantitative PCR primers

\begin{tabular}{|c|c|c|c|c|c|}
\hline Gene & $\begin{array}{l}\text { GenBank } \\
\text { accession no. }\end{array}$ & $\begin{array}{l}\text { Amplicon } \\
\text { size (bp) }\end{array}$ & $\begin{array}{c}\text { Annealing } \\
\text { temperature }\left({ }^{\circ} \mathrm{C}\right)\end{array}$ & Sequence $\left(5^{\prime} \rightarrow 3^{\prime}\right)$ & References \\
\hline FAS & AY183428 & 196 & 58 & $\begin{array}{l}\text { F: AGC CTA ACT CCT CGC TGC AAT } \\
\text { R: TCC TTG GAA CCG TCT GTG TTC }\end{array}$ & Zhao et al. ${ }^{(30)}$ \\
\hline ACC & EF618729 & 133 & 60 & $\begin{array}{l}\text { F: ATG TTT CGG CAG TCC CTG AT } \\
\text { R: TGT GGA CCA GCT GAC CTT GA }\end{array}$ & Zhao et al. ${ }^{(30)}$ \\
\hline ATP-CL & NM001105302 & 94 & 61 & $\begin{array}{l}\text { F: ATC TGG GAG GTG TCA ACG AGC } \\
\text { R: GAG AGG ATG GTC TTG GCA TAG TC }\end{array}$ & Present study \\
\hline GADPH & AF017079 & 100 & 60 & $\begin{array}{l}\text { F: ACTCACTCTTCTACCTTTGATGCT } \\
\text { R: TGTTGCTGTAGCCAAATTCA }\end{array}$ & Present study \\
\hline
\end{tabular}

FAS, fatty acid synthase; F, forward; R, reverse; ACC, acetyl CoA carboxylase; ATP-CL, ATP-citrate lyase; GAPDH, glyceraldehyde-3-phosphate dehydrogenase. 


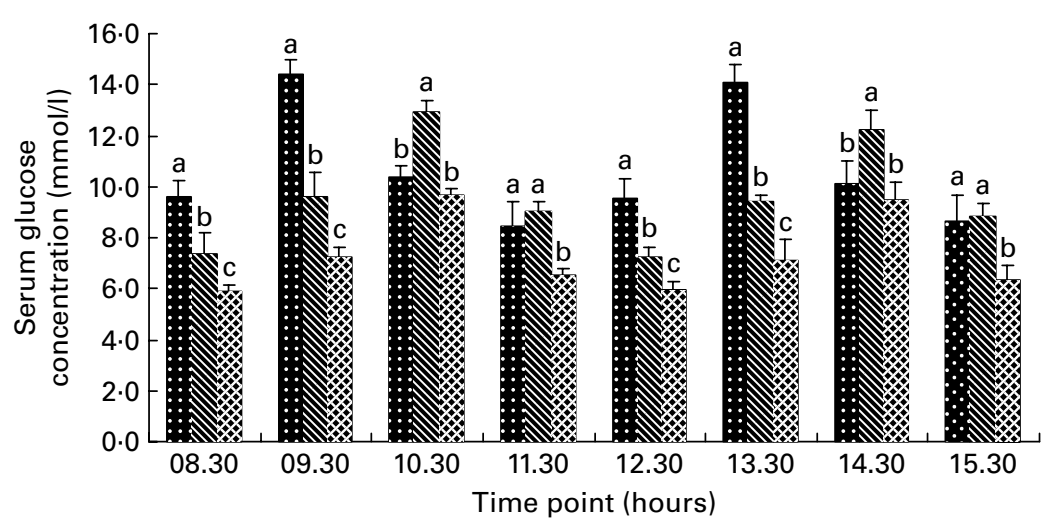

Fig. 1. Variation in postprandial serum systemic circulating glucose in two feeding cycles. $\mathbf{D}$, High-digestion rate starch group; $\mathbf{s}$, moderate-digestion rate starch group; low-digestion rate starch group. ${ }^{\mathrm{a}, \mathrm{b}, \mathrm{c}}$ Mean values within the same sampling time with unlike letters were significantly different $(n 8, P<0.05)$.

$R=2^{\text {(CT(GAPDH) }-\mathrm{CT}(\mathrm{test}))(31)}$. The amplification efficiency $(E)$ of the quantitative PCR was acquired by the amplification of a dilution series of complementary DNA according to the equation $E=10^{(-1 / \text { slope })}$ and was consistent between the target mRNA and GAPDH rRNA. Negative controls were performed in which complementary DNA was replaced with water $^{(32)}$.

\section{Statistical analyses}

All physico-chemical analyses were performed at least in duplicate. The data on the serum biochemical parameters were analysed as a split-plot design for repeated measures using the generalised linear model procedure of SAS 9.13 (SAS Institute, Inc., Cary, NC, USA). The statistical model included the effect of treatment as the main plot (tested by the animal within treatment variance) and the effects of sampling time and the treatment $\times$ sampling time interaction as the subplot. The comparisons among treatments within sampling time were made when a significant $F$ test $(P<0.05)$ for the treatment $\times$ sampling time interaction was observed. The data on the variation in the activities and mRNA expression of FAS, ACC and ATP-CL were also analysed as a split-plot design for repeated measures. The statistical model included the effect of treatment as the main plot and the effects of tissues and the treatment $\times$ tissue interaction as the subplot. The comparisons among treatments within tissues were made when a significant $F$ test $(P<0.05)$ for the treatment $\times$ tissue interaction was observed. The Duncan's multiple comparison test was used to determine the differences among the means of treatment groups. A value of $P<0.05$ was considered to be statistically significant.

\section{Results}

\section{Serum circulating glucose and insulin}

The variation in postprandial systemic circulating glucose and insulin is summarised in Figs. 1 and 2, respectively. Both glucose and insulin were affected $(P<0.05)$ by the sampling time as well as by the treatment $\times$ sampling time interaction, and changed periodically in response to the present feeding procedure. Furthermore, the serum level of glucose in pigs of the HDRS group was increased sharply to the peak point (at postprandial $1.5 \mathrm{~h}$ ), while that in the MDRS and LDRS groups were increased slowly to their peak points at postprandial $2.5 \mathrm{~h}$, respectively. The peak level of glucose in the HDRS group was higher $(P<0.05)$ than that in the MDRS group, and that in the MDRS group was also higher $(P<0.05)$ than in the LDRS group. The serum insulin levels in the three dietary treatment groups were increased quickly to the peak point, and

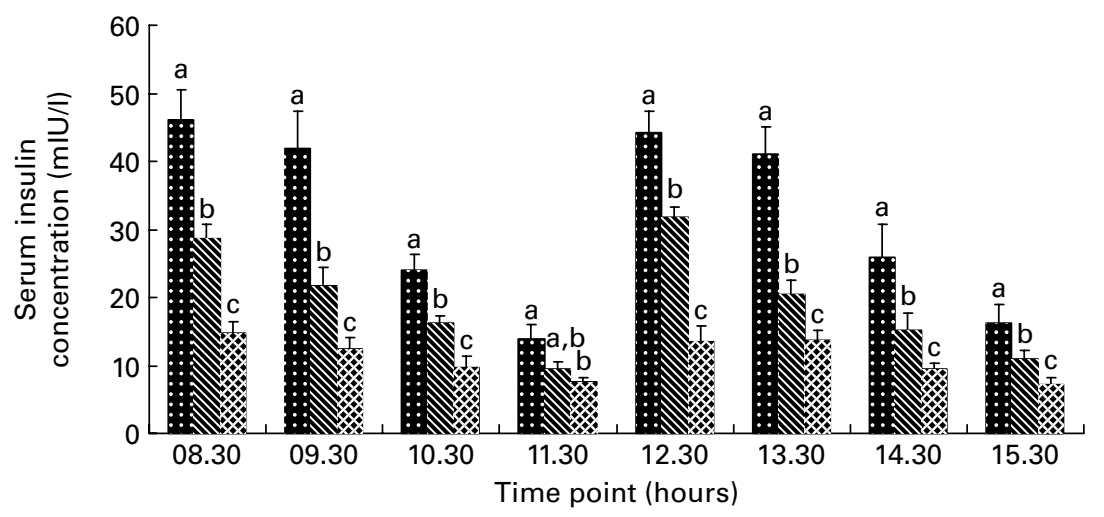

Fig. 2. Variation in postprandial serum systemic circulating insulin concentration in two feeding cycles. $\mathbf{D}$, High-digestion rate starch group; $\mathbf{N}$, moderate-digestion rate starch group; $\mathbf{0}$, low-digestion rate starch group. ${ }^{\mathrm{a}, \mathrm{b}, \mathrm{c}}$ Mean values within the same sampling time with unlike letters were significantly different $(n 8, P<0.05)$. $1 \mathrm{mIU}=6.945 \mu \mathrm{mol}$. 
then decreased gradually within each feeding cycle; however, the variation in insulin level did not respond simultaneously to the postprandial blood glucose levels. The serum insulin concentration in the HDRS group was higher $(P<0.05)$ than that in the MDRS group, and that in the MDRS group was also higher $(P<0.05)$ than in the LDRS group at postprandial 0.5 , 1.5 and $2.5 \mathrm{~h}$, respectively. During the second feeding cycle, from 12.30 to 15.30 hours, the variation in postprandial systemic circulating glucose and insulin was similar to that observed during the first feeding cycle, from 08.30 to 11.30 hours.

\section{Serum circulating lipid profiles and SCFA}

The postprandial serum concentrations of lipid and SCFA were also affected $(P<0.05)$ by both the sampling time and the treatment $\times$ sampling time interaction (Tables 3 and 4 ), and changed periodically in response to the present feeding procedure. The serum levels of TAG, total cholesterol, LDLcholesterol and HDL-cholesterol in the HDRS group were increased to the peak point at postprandial 2.5, 2.5, 1.5 and $1.5 \mathrm{~h}$, those in the MDRS group were at postprandial $3.5,3.5$, 3.5 and $3.5 \mathrm{~h}$ and those in the LDRS group were at postprandial $3.5,3.5,1.5$ and $3.5 \mathrm{~h}$, respectively. Furthermore, the serum TAG level in the HDRS group was higher $(P<0.05)$ than that in the MDRS group at postprandial 1.5 and $2.5 \mathrm{~h}$, and was even higher $(P<0.05)$ than that in the LDRS group at different time points postprandially, and that in the MDRS group was higher $(P<0.05)$ than that in the LDRS group at postprandial $3.5 \mathrm{~h}$ in the first feeding cycle. The serum TAG level in the MDRS group was lower $(P<0.05)$ than that in the MDRS group at postprandial $3.5 \mathrm{~h}$, and was higher $(P<0.05)$ than that in the LDRS group at postprandial 1.5 , 2.5 and $3.5 \mathrm{~h}$; the serum TAG level in the MDRS group was higher $(P<0.05)$ than that in the LDRS group at different time points postprandially in the second feeding cycle, respectively. The serum levels of total cholesterol and HDLcholesterol in the HDRS group were higher $(P<0.05)$ than those in the MDRS group at postprandial $0.5,1.5$ and $2.5 \mathrm{~h}$, and those in the MDRS group were higher $(P<0.05)$ than those in the LDRS group at different time points postprandially. The serum LDL-cholesterol level in the HDRS group was lower $(P<0.05)$ than that in the MDRS group at postprandial $0.5,2.5$ and $3.5 \mathrm{~h}$, and was higher $(P<0.05)$ than that in the LDRS group at postprandial $1.5 \mathrm{~h}$, and that in the MDRS group was higher $(P<0.05)$ than that in the LDRS group at different time points postprandially in the first feeding cycle; the serum LDL-cholesterol level in the MDRS group was lower $(P<0.05)$ than that in the MDRS group at postprandial 2.5 and $3.5 \mathrm{~h}$, and was higher $(P<0.05)$ than that in the LDRS group at postprandial $1.5 \mathrm{~h}$, and that in the MDRS group was higher $(P<0.05)$ than that in the LDRS group at postprandial $0.5,2.5$ and $3.5 \mathrm{~h}$, respectively. The serum acetate, propionate and butyrate levels in pigs of the HDRS and MDRS groups increased to the peak point sharply, at postprandial $1.5 \mathrm{~h}$; those in the LDRS group increased to the peak points at postprandial $2.5 \mathrm{~h}$, respectively. Similar results were observed during the second feeding cycle, from 12.30 to 15.30 hours.

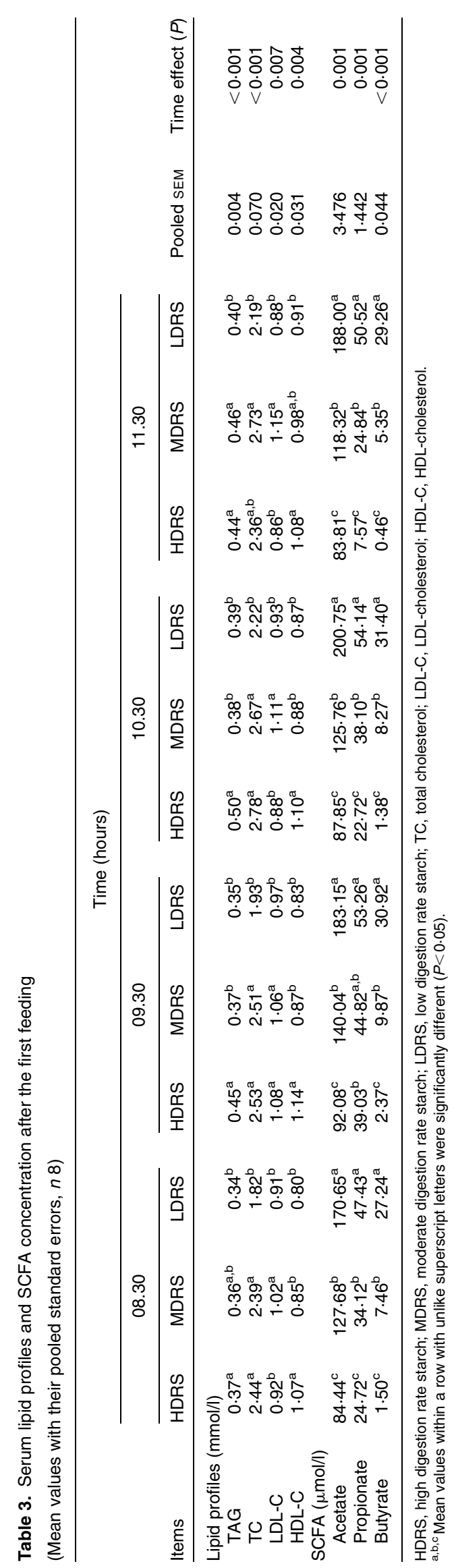




\section{Activities of lipogenic enzymes}

The activities of the lipogenic enzymes were affected $(P<0.05)$ by the tissue and the treatment $\times$ tissue interaction (Table 5). The activity of FAS in the myocardium, liver, abdominal adipose and interscapular brown adipose tissues of pigs of the HDRS and MDRS groups was higher $(P<0.05)$ than that of the LDRS group; that in the liver and abdominal adipose tissues of the HDRS group was also higher $(P<0.05)$ than that of the MDRS group. The activity of ACC in the myocardium, liver, abdominal adipose and interscapular brown adipose tissues of pigs of the HDRS group and that in the myocardium, liver and abdominal adipose tissues of the MDRS group were higher $(P<0.05)$ than that of the LDRS group; the activity of ACC in the myocardial adipose and interscapular brown adipose tissues of the HDRS group was higher $(P<0.05)$ than that of the MDRS group. The activity of ATP-CL in the myocardium, liver, abdominal adipose and interscapular brown adipose tissues of pigs of the HDRS group and that in the myocardium and liver of the MDRS group were higher $(P<0.05)$ than that of the LDRS group; the activity of ATP$\mathrm{CL}$ in the liver and interscapular brown adipose of the HDRS group was higher $(P<0.05)$ than that of the MDRS group.

\section{mRNA levels of lipid metabolism-related genes}

The mRNA levels of the lipid metabolism-related genes were affected $(P<0.05)$ by the tissue and the treatment $\times$ tissue interaction (Table 6). The mRNA level of FAS in the myocardium, liver, abdominal adipose and interscapular brown adipose tissues of pigs of the HDRS group and that in the myocardium, abdominal adipose and interscapular brown adipose tissues of the MDRS group were higher $(P<0.05)$ than that of the LDRS group; the mRNA level in the myocardium, liver and interscapular brown adipose tissues of the HDRS group was also higher $(P<0 \cdot 05)$ than that of the MDRS group. The mRNA level of ACC in the myocardium, liver, abdominal adipose and interscapular brown adipose tissues of pigs of the HDRS and MDRS group was higher $(P<0 \cdot 05)$ than that of the LDRS group; that in the myocardium and abdominal adipose tissue of the HDRS group was higher $(P<0.05)$ than that of the MDRS group. The mRNA level of ATP-CL in the myocardium, liver, abdominal adipose and interscapular brown adipose tissues of the HDRS and MDRS group was higher $(P<0.05)$ than that of the LDRS group; that in the liver, abdominal adipose and interscapular brown adipose tissues was higher $(P<0 \cdot 05)$ than that of the MDRS group.

\section{Discussion}

Animal nutrition researchers have been trying to develop novel strategies to get maximal deposition of carbon, nitrogen as well as other nutrients in food animals, of which elevating the postprandial circulating levels of insulin, glucose and amino acids has been proved to be practical in mammals ${ }^{(33,34)}$. An important observation from the present study was that the postprandial circulating levels of glucose and insulin were changed periodically in response to the 'six-time intake/d' 
Table 5. Activity of the lipogenic enzymes after pigs consumed the experimental diets ( $\mathrm{nmol} / \mathrm{min}$ per $\mathrm{mg}$ protein)

(Mean values with their pooled standard errors, $n$ 8)

\begin{tabular}{|c|c|c|c|c|c|c|c|c|c|c|c|c|c|c|}
\hline \multirow{3}{*}{$\begin{array}{l}\text { Lipogenic } \\
\text { enzymes }\end{array}$} & \multicolumn{12}{|c|}{ Tissues } & \multirow{3}{*}{$\begin{array}{l}\text { Pooled } \\
\text { SEM }\end{array}$} & \multirow{3}{*}{$\begin{array}{l}\text { Tissue } \\
\text { effect }(P\end{array}$} \\
\hline & \multicolumn{3}{|c|}{ Myocardium } & \multicolumn{3}{|c|}{ Liver } & \multicolumn{3}{|c|}{ Abdominal adipose } & \multicolumn{3}{|c|}{$\begin{array}{c}\text { Interscapular brown } \\
\text { adipose }\end{array}$} & & \\
\hline & HDRS & MDRS & LDRS & HDRS & MDRS & LDRS & HDRS & MDRS & LDRS & HDRS & MDRS & LDRS & & \\
\hline FAS & $4.04^{a}$ & $3.41^{\mathrm{a}}$ & $1 \cdot 39^{b}$ & $6 \cdot 87^{a}$ & $4 \cdot 78^{b}$ & $2 \cdot 36^{c}$ & $34 \cdot 34^{\mathrm{a}}$ & $23.88^{b}$ & $11 \cdot 81^{\mathrm{c}}$ & $24 \cdot 10^{a}$ & $21.94^{a}$ & $12 \cdot 47^{\mathrm{b}}$ & 0.773 & 0.006 \\
\hline $\mathrm{ACC}$ & $3.35^{a}$ & $2 \cdot 61^{b}$ & $0.61^{c}$ & $4 \cdot 36^{a}$ & $4 \cdot 19^{a}$ & $1.04^{\mathrm{b}}$ & $21 \cdot 79^{a}$ & $20 \cdot 95^{a}$ & $5 \cdot 20^{\mathrm{b}}$ & $25 \cdot 68^{a}$ & $11 \cdot 20^{\mathrm{b}}$ & $7.79^{b}$ & 1.020 & 0.045 \\
\hline ATP-CL & $3 \cdot 33^{a}$ & $2 \cdot 71^{a}$ & $1 \cdot 34^{b}$ & $6 \cdot 67^{a}$ & $4 \cdot 61^{b}$ & $2.55^{\mathrm{c}}$ & $33.33^{a}$ & $23.05^{a, b}$ & $12 \cdot 77^{\mathrm{b}}$ & $17 \cdot 48^{\mathrm{a}}$ & $10 \cdot 18^{b}$ & $7 \cdot 88^{b}$ & 1.231 & 0.004 \\
\hline
\end{tabular}

HDRS, high digestion rate starch; MDRS, moderate digestion rate starch; LDRS, low digestion rate starch; FAS, fatty acid synthase; ACC, acetyl CoA carboxylase; ATP-CL, ATP-citrate lyase.

${ }^{a, b, c}$ Mean values within a row with unlike superscript letters were significantly different $(P<0.05)$.

feeding procedure. Besides, about $81 \cdot 90,47 \cdot 17$ and $30 \cdot 14 \%$ of dietary starch were digested in the anterior jejunum of pigs in the HDRS, MDRS and LDRS groups, respectively ${ }^{(6)}$. The higher starch digestibility in the anterior small intestine results in higher and rapid postprandial circulating glucose and insulin responses ${ }^{(35)}$. Since insulin is secreted primarily in response to the elevated blood glucose concentration, stimulated by the feeding frequency and activity ${ }^{(36,37)}$, and even controlled by the central nervous system through some signal pathways $^{(38)}$, the difference in the postprandial serum insulin levels in the present study should be a combined result of both the feeding activity and the efficiency of glucose absorption. In other words, there is a clear correlation between the starch digestibility and the insulin response for the three diets.

Lipogenesis is a process by which simple sugars such as glucose are converted to fatty acids ${ }^{(39)}$, which is regulated by a wide array of interdependent factors, including nutrients, hormones, nuclear transcription factors and lipogenic enzymes, of which glucose and insulin are two important regulating molecules $^{(40,41)}$. In this regard, the postprandial circulating lipid profile may reflect how blood glucose and insulin affected the lipid metabolism. An important finding from the present study is that the postprandial circulating levels of lipids and SCFA were also changed periodically. Interestingly, the higher the starch digestion rate was, the faster the postprandial circulating levels of TAG, total cholesterol and HDL-cholesterol responded, and the lower the circulating levels of SCFA responded. Insulin promotes the synthesis of fatty acids in the liver and inhibits the breakdown of fat in the adipose tissue by inhibiting the intracellular lipase that hydrolyses
TAG to release fatty acids ${ }^{(42)}$, and high glucose induces adipogenic differentiation in porcine ${ }^{(40)}$, as well as in human tissues $^{(43)}$. Therefore, the higher level of postprandial glucose and insulin stimulated the process of adipogenesis and elevated the circulating lipid profiles. SCFA are the major end products of bacterial metabolism in the large intestine of animals ${ }^{(44,45)}$, which stimulate adipogenesis via the $G$ proteincoupled receptor 43 pathway ${ }^{(46)}$. In the present study, lower levels of postprandial circulating lipid profiles were observed in pigs of the LDRS group with higher levels of fatty acids at the same time. The lower availability of glucose would result in higher oxidation of other nutrients, such as protein and lipids, for energy requirement ${ }^{(47,48)}$, which may explain the lower concentration of serum lipids in pigs of the LDRS group, and a similar phenomenon was observed previously in rats ${ }^{(49)}$, as well as in mice ${ }^{(50)}$.

Lipids are considered to be crucial in the metabolic process of mammals ${ }^{(51,52)}$. There are two sources of lipids for metabolism, exogenously derived (dietary) lipids and endogenously synthesised lipids ${ }^{(53)}$. The biosynthesis of the latter (lipogenesis) depends on well-known enzyme-regulated processes, of which FAS, ACC and ATP-CL are the primary lipogenic enzymes, and were considered as rate-limiting enzymes of lipogenesis in pigs ${ }^{(54,55)}$. A novel finding of the present study was that the activities of FAS, ACC and ATP-CL in the myocardium, liver, abdominal adipose and interscapular brown adipose in pigs of the HDRS group were higher than those in the MDRS and LDRS groups, and these results are, at least partially, in accordance with the gene expression profiles of these enzymes. Metabolic regulation in mammals relies

Table 6. Relative key lipogenic enzyme gene expression profiles after pigs consumed the experimental diets (arbitrary units)

(Mean values with their pooled standard errors, $n 8$ )

\begin{tabular}{|c|c|c|c|c|c|c|c|c|c|c|c|c|c|c|}
\hline \multirow{3}{*}{$\begin{array}{l}\text { Lipogenic } \\
\text { enzymes }\end{array}$} & \multicolumn{12}{|c|}{ Tissues } & \multirow{3}{*}{$\begin{array}{l}\text { Pooled } \\
\text { SEM }\end{array}$} & \multirow{3}{*}{$\begin{array}{l}\text { Tissue } \\
\text { effect }(P)\end{array}$} \\
\hline & \multicolumn{3}{|c|}{ Myocardium } & \multicolumn{3}{|c|}{ Liver } & \multicolumn{3}{|c|}{$\begin{array}{l}\text { Abdominal } \\
\text { adipose }\end{array}$} & \multicolumn{3}{|c|}{$\begin{array}{l}\text { Interscapular brown } \\
\text { adipose }\end{array}$} & & \\
\hline & HDRS & MDRS & LDRS & HDRS & MDRS & LDRS & HDRS & MDRS & LDRS & HDRS & MDRS & LDRS & & \\
\hline FAS & $1 \cdot 17^{\mathrm{a}}$ & $0.84^{\mathrm{b}}$ & $0.49^{c}$ & $1.23^{\mathrm{a}}$ & $0.93^{\mathrm{b}}$ & $0.85^{\mathrm{b}}$ & $1.45^{\mathrm{a}}$ & $1 \cdot 32^{\mathrm{a}}$ & $0.25^{\mathrm{b}}$ & $1.28^{a}$ & $0.89^{\mathrm{b}}$ & $0.44^{c}$ & 0.026 & $<0.001$ \\
\hline ACC & $1 \cdot 14^{\mathrm{a}}$ & $0.97^{b}$ & $0.80^{\mathrm{C}}$ & $1.38^{\mathrm{a}}$ & $1.25^{\mathrm{a}}$ & $0.38^{\mathrm{b}}$ & $1 \cdot 88^{\mathrm{a}}$ & $0.82^{\mathrm{b}}$ & $0.57^{\mathrm{C}}$ & $1.55^{\mathrm{a}}$ & $1.49^{\mathrm{a}}$ & $0.37^{\mathrm{b}}$ & 0.015 & 0.005 \\
\hline ATP-CL & $0.91^{a}$ & $0.78^{a}$ & $0.32^{\mathrm{b}}$ & $1 \cdot 31^{\mathrm{a}}$ & $1 \cdot 13^{b}$ & $0.92^{c}$ & $1 \cdot 82^{a}$ & $1.06^{\mathrm{b}}$ & $0.82^{c}$ & $1.49^{\mathrm{a}}$ & $0.37^{\mathrm{b}}$ & $0.94^{a}$ & 0.022 & $<0.001$ \\
\hline
\end{tabular}


partly on transcriptional control of the expression level of key enzymes $^{(56)}$, and gene expression analysis is useful for inferring transcriptional activity. Glucose is known to directly affect lipogenic gene expression by altering the transcriptional repressor level via the lipid synthesis pathway in a range of tissues $^{(57)}$, while insulin regulates the lipogenic gene expression indirectly, either by increasing glucose transportation and metabolism through the translocation of the insulinresponsive GLUT-4 to the plasma membrane in adipocytes or by speeding up glucose metabolism in the liver through the activated glucokinase pathway ${ }^{(58)}$. In the present study, the mRNA levels of FAS, ACC and ATP-CL in the myocardium, liver, abdominal adipose and interscapular brown adipose in pigs of the HDRS group were higher than those of the LDRS group, corresponding with the postprandial circulating glucose and insulin responses in these groups. However, an interesting observation was that not only the mRNA levels but also the activities of these rate-limiting lipogenic enzymes in the same tissue were significantly different. Furthermore, the mRNA level and the activity of the same lipogenic enzyme gene in different tissues were also different. These significant differences may be due to the different functions of these lipogenic enzymes, different responses of these enzymes to blood glucose and insulin and different metabolic patterns of lipids in these tissues ${ }^{(59-62)}$

In summary, the present study shows that dietary starch with a higher digestion rate significantly elevated the postprandial blood glucose and insulin response, and also the profiles of circulating lipids but not of SCFA. Glucose and insulin have a priority in regulating lipogenesis in different tissues over that of SCFA. The activity of lipogenic enzymes and their gene expression were affected by the postprandial circulating glucose and insulin in weaned pigs.

\section{Acknowledgements}

The present study was jointly supported by grants from the National 863 project (2008AA10Z316), the National Natural Science Foundation of China (30901040, 30928018), the Cooperative Projects of Guangdong Province and Chinese Academy of Science (2009B091300043, 2009B091300079, 2009B091300089). The authors are grateful to all staff in the Laboratory of Animal Nutritional Physiology and Metabolic Process, Institute of Subtropical Agriculture, the Chinese Academy of Sciences for their assistance in the present study. Y. Y. was in charge of the whole trial. F. Y. and Z. Z. conducted the animal experiment and wrote the manuscript. J. H., R. H. and T. L. assisted with the animal trial and laboratory analyses. The authors have no conflicts of interest.

\section{References}

1. Knudsen KEB, Lærke HN, Steenfeldt $\mathrm{S}$, et al. (2006) In vivo methods to study the digestion of starch in pigs and poultry. Anim Feed Sci Technol 130, 114-135.

2. Wiseman J (2006) Variations in starch digestibility in nonruminants. Anim Feed Sci Technol 130, 66-77.
3. Annison G \& Topping DL (1994) Nutritional role of resistant starch: chemical structure vs. physiological function. Annu Rev Nutr 14, 297-320.

4. Robertson JA (1988) Physicochemical characteristics of food and the digestion of starch and dietary fibre during gut transit. Proc Nutr Soc 47, 143-152.

5. Yang CZ, Shu XL, Zhang LL, et al. (2006) Starch properties of mutant rice high in resistant starch. J Agric Food Chem 54, $523-528$.

6. Yin F, Zhang Z, Huang J, et al. (2010) Digestion rate of dietary starch affects systemic circulation of amino acids in weaned pigs. Br J Nutr 103, 1404-1412.

7. Gary MG (1992) Starch digestion and absorption in nonruminants. J Nutr 22, 172-177.

8. Yin F, Huang J, Zhang Z, et al. (2009) Determination of digestion rates of dietary starches by in vivo and in vitro method and their effects on physiologic status of weanling pig. In Proceedings of 4 th International Symposium on Animal Nutrition, Health and Feed Additive, Guangzhou, China, pp. 509.

9. Regmi PR, Matte JJ, van Kempen TATG, et al. (2010) Starch chemistry affects kinetics of glucose absorption and insulin response in swine. Livest Sci $\mathbf{1 3 4}, 44-46$.

10. Bin SY (2005) The effect of dietary starch sources on growth performance, starch digestion in small intestine and splanchnic tissues protein synthesis of weaned pigs. PhD Thesis, Sichuan Agricultural University.

11. Dai QZ (2005) The effect of dietary starch source on ileum digestibility, net portal absorption and pattern of amino acids in growing pigs. PhD Thesis, Sichuan Agricultural University.

12. Wilfart A, Montagne L, Simmins H, et al. (2007) Digesta transit in different segments of the gastrointestinal tract of pigs as affected by insoluble fibre supplied by wheat bran. Br J Nutr 98, 54-62.

13. Wiggins HS (1984) Nutritional value of sugars and related compounds undigested in the small gut. Proc Nutr Soc $\mathbf{4 3}$, 69-75.

14. Cummings JH \& Macfarlane GT (1997) Role of intestinal bacteria in nutrient metabolism. Clin Nutr 16, 3-11.

15. Darcy-Vrillon B, Cherbuy C, Morel MT, et al. (1996) Short chain fatty acid and glucose metabolism in isolated pig colonocytes: modulation by $\mathrm{NH}^{4+}$. Mol Cell Biochem 156, $145-151$.

16. Leturque A, Postic C, Ferre P, et al. (1991) Nutritional regulation of glucose transporter in muscle and adipose tissue of weaned rats. Am J Physiol Endocrinol Metab 260, E588-E593.

17. Li J, Yu X, Pan W, et al. (2002) Gene expression profile of rat adipose tissue at the onset of high-fat-diet obesity. Am J Physiol Endocrinol Metab 282, E1334-E1341.

18. Louveau I \& Gondret F (2004) GH and insulin affect fatty acid synthase activity in isolated porcine adipocytes in culture without any modifications of sterol regulatory element binding protein-1 expression. J Endocrinol 181, 271-280.

19. Dunshea FR (1993) Effect of metabolism modifiers on lipid metabolism in the pig. J Anim Sci 71, 1966-1977.

20. Foufelle F, Gouhot B, Pégorier JP, et al. (1992) Glucose stimulation of lipogenic enzyme gene expression in cultured white adipose tissue. A role for glucose 6-phosphate. J Biol Chem 267, 20543-20546.

21. Fukuda H, Katsurada A \& Iritani N (1992) Nutritional and hormonal regulation of mRNA levels of lipogenic enzymes in primary cultures of rat hepatocytes. $J$ Biochem 111, 25-30. 
22. Huang RL, Yin YL, Wang KP, et al. (2003) Nutritional value of fermented and not fermented material of distiller's grains in pig nutrition. J Anim Food Sci 12, 261-269.

23. Li TJ, Dai QZ, Yin YL, et al. (2008) Dietary starch sources affect net portal appearance of amino acids and glucose in growing pigs. Animal 2, 723-729.

24. National Research Council (1998) Nutrient Requirements of Swine. Washington, DC: National Academy Press.

25. Swierczynski J, Goyke E, Wach L, et al. (2000) Comparative study of the lipogenic potential of human and rat adipose tissue. Metabolism 149, 594-599.

26. Zelewski M \& Swierczynski J (1990) Comparative studies on lipogenic enzyme activities in brown adipose tissue and liver of rat during starvation-refeeding transition and cold exposure. Comp Biochem Physiol 197B, 59-63.

27. Salati LM \& Clarke DE (1986) Fatty acid inhibition of hormonal induction of acetyl-coenzyme A carboxylase in hepatocyte monolayers. Arch Biochem Biophys 246, 82-89.

28. Bradford MM (1976) A rapid and sensitive method for the quantitation of microgram quantities of protein utilizing the principle of protein-dye binding. Anal Biochem 72, 248-254.

29. Wang W, Gu W, Tang X, et al. (2009) Molecular cloning, tissue distribution and ontogenetic expression of the amino acid transporter $b^{0,+}$ cDNA in the small intestine of Tibetan suckling piglets. Comp Biochem Physiol B 154, 157-164.

30. Zhao S, Wang J, Song X, et al. (2010) Impact of dietary protein on lipid metabolism-related gene expression in porcine adipose tissue. Nutr Metab 7, 6.

31. Livak KJ \& Schmittgen TD (2001) Analysis of relative gene expression data using real-time quantitative PCR and the 2(-Delta Delta C (T)) method. Methods 25, 402-408.

32. Wang WC, Shi CY, Zhang JS, et al. (2009) Molecular cloning, distribution and ontogenetic expression of the oligopeptide transporter PepT1 mRNA in Tibetan suckling piglets. Amino Acids 37, 593-601.

33. Jeyapalan AS, Orellana RA, Suryawan A, et al. (2007) Glucose stimulates protein synthesis in skeletal muscle of neonatal pigs through an AMPK- and mTOR-independent process. Am J Physiol Endocrinol Metab 293, E595-E603.

34. Tremblay F \& Marette A (2001) Amino acid and insulin signaling via the mTOR/p70 S6 kinase pathway. $J$ Biol Chem 276, 38052-38060.

35. Deng J, Wu X, Bin S, et al. (2010) Dietary amylose and amylopectin ratio and resistant starch content affects plasma glucose, lactic acid, hormone levels and protein synthesis in splanchnic tissues. J Anim Physiol Anim Nutr 94, 220-226.

36. Solomon TPJ, Chambers ES, Jeukendrup AE, et al. (2008) The effect of feeding frequency on insulin and ghrelin responses in human subjects. Br J Nutr 100, 810-819.

37. Armentano LE, Mills SE \& de Boer G (1984) Effects of feeding frequency on glucose concentration, glucose turnover, and insulin concentration in steers. J Dairy Sci 67, 1445-1451.

38. Shankar R, Zhu JS, Ladd B, et al. (1998) Central nervous system nitric oxide synthase activity regulates insulin secretion and insulin action. J Clin Invest 102, 1403-1412.

39. Kersten S (2001) Mechanisms of nutritional and hormonal regulation of lipogenesis. EMBO Rep 2, 282-286.

40. Yue T, Yin J, Li F, et al. (2010) High glucose induces differentiation and adipogenesis in porcine muscle satellite cells via mTOR. BMB Rep 43, 140-145.

41. Zhang HH, Huang J, Dúvel K, et al. (2009) Insulin stimulates adipogenesis through the Akt-TSC2-mTORC1 pathway. PLOS ONE 4, 1-14.

42. Marshall S (2006) Role of insulin, adipocyte hormones, and nutrient-sensing pathways in regulating fuel metabolism and energy homeostasis: a nutritional perspective of diabetes, obesity, and cancer. Sci STKE $\mathbf{2 0 0 6}$, re7.

43. Wang W, Zhang X, Zheng J, et al. (2010) High glucose stimulates adipogenic and inhibits osteogenic differentiation in MG-63 cells through cAMP/protein kinase A/extracellular signal-regulated kinase pathway. Mol Cell Biochem 338 , $115-122$.

44. Macfarlane S \& Macfarlane GT (2003) Regulation of shortchain fatty acid production. Proc Nutr Soc 62, 67-72.

45. Cummings JH, Pomare EW, Branch WJ, et al. (1987) Short chain fatty acids in human large intestine, portal, hepatic and venous blood. Gut 28, 1221-1227.

46. Hong YH, Nishimura Y, Hishikawa D, et al. (2005) Acetate and propionate short chain fatty acids stimulate adipogenesis via GPCR43. Endocrinology 146, 5092-5099.

47. Higgins JA, Higbee DR, Donahoo WT, et al. (2004) Resistant starch consumption promotes lipid oxidation. Nutr Metab $\mathbf{1}, 8$.

48. Jéquier E (1998) Effect of lipid oxidation on glucose utilization in humans. Am J Clin Nutr 67, 527S-530S.

49. Kabir M, Rizkalla SW, Champ M, et al. (1998) Dietary amylose-amylopectin starch content affects glucose and lipid metabolism in adipocytes of normal and diabetic rats. $J$ Nutr 128, 35-43.

50. So PW, Yu WS, Kuo YT, et al. (2007) Impact of resistant starch on body fat patterning and central appetite regulation. PLOS ONE 2, e1309.

51. Wisneski JA, Gertz EW, Neese RA, et al. (1987) Myocardial metabolism of free fatty acids. J Clin Invest 79, 359-366.

52. Martinez-Puig D, Mourot J, Ferchaud-Roucher V, et al. (2006) Consumption of resistant starch decreases lipogenesis in adipose tissues but not in muscular tissues of growing pigs. Livest Sci 99, 237-247.

53. Ortega FJ, Mayas D, Moreno-Navarrete JM, et al. (2010) The gene expression of the main lipogenic enzymes is downregulated in visceral adipose tissue of obese subjects. Obesity 18, 13-20.

54. Scott RA, Cornelius SG \& Mersmann HJ (1981) Effects of age on lipogenesis and lipolysis in lean and obese swine. J Anim Sci 52, 505-511.

55. Huang QC, Xu ZR, Han XY, et al. (2008) Effect of dietary betaine supplementation on lipogenic enzyme activities and fatty acid synthase mRNA expression in finishing pigs. Anim Feed Sci Technol 140, 365-375.

56. Desvergne B, Michalik L \& Wahli W (2006) Transcriptional regulation of metabolism. Physiol Rev 86, 465-514.

57. Hasegawa J, Osatomi K, Wu RF, et al. (1999) A novel factor binding to the glucose response elements of liver pyruvate kinase and fatty acid synthase genes. J Biol Chem 274, 1100-1107.

58. Weickert MO \& Pfeiffer AFH (2006) Signalling mechanisms linking hepatic glucose and lipid metabolism. Diabetologia 49, 1732-1741.

59. Nguyen P, Leray V, Diez M, et al. (2008) Liver lipid metabolism. J Anim Physiol Anim Nutr 92, 272-283.

60. Owen OE, Kalhan SC \& Hanson RW (2002) The key role of anaplerosis and cataplerosis for citric acid cycle function. J Biol Chem 277, 30409-30412.

61. Colombo C, Cutson JJ, Yamauchi T, et al. (2002) Transplantation of adipose tissue lacking leptin is unable to reverse the metabolic abnormalities associated with lipoatrophy. Diabetes 51, 2727-2733.

62. Gaikwad A, Long DJ, Stringer JL, et al. (2001) In vivo role of $\mathrm{NAD}(\mathrm{P}) \mathrm{H}$ : quinone oxidoreductase 1 (NQO1) in the regulation of intracellular redox state and accumulation of abdominal adipose tissue. J Biol Chem 276, 22559-22564. 